\title{
Renegotiation and Stabilization Clauses in Nigeria's Upstream Petroleum Industry's Contracts: The Issues and the Options
}

OLUSOLA JOSHUA OLUJOBI ( $\sim$ olusola.olujobi@covenantuniversity.edu.ng )

\section{Research}

Keywords: Contracts, Renegotiation, Stabilization Clauses, Petroleum Industry, Nigeria

Posted Date: April 22nd, 2020

DOI: https://doi.org/10.21203/rs.3.rs-21817/v2

License: (c) (i) This work is licensed under a Creative Commons Attribution 4.0 International License.

Read Full License 
The authors have withdrawn this preprint from Research Square 